\title{
Ahead of Its Time? Reflecting on New Zealand's Pharmac Following Its 20th Anniversary
}

\author{
Robin Gauld
}

Published online: 7 June 2014

(C) Springer International Publishing Switzerland 2014

\begin{abstract}
New Zealand's Pharmaceutical Management Agency (Pharmac) was created in 1993. Unusual in international terms, Pharmac's objective is to work within a fixed budget while ensuring the New Zealand public receives an adequate range of government-subsidised medicines. Following its 20th anniversary, this article reflects on Pharmac's development and role within the New Zealand health system, various changes over time to the agency's scope and activities, its performance and its present challenges.
\end{abstract}

\section{Key Points for Decision Makers}

New Zealand's Pharmac is unusual internationally in that it actively manages a list of publicly-subsidised pharmaceuticals on behalf of the government within a fixed annual budget

Pharmac assesses the effectiveness of pharmaceutical products and negotiates prices with suppliers before agreeing to list and subsidise them

Pharmac has been successful in keeping costs down but has been criticised for limiting access to some medicines, or delaying their availability

R. Gauld ( $\square)$

Department of Preventive and Social Medicine, Centre for Health Systems, University of Otago, PO Box 56, Dunedin 9054, New Zealand

e-mail: robin.gauld@otago.ac.nz

\section{Introduction}

New Zealand's Pharmaceutical Management Agency (Pharmac) was created in 1993. For more than two decades, it has performed extremely well in terms of delivering tax-payer subsidised medicines to the New Zealand public. It has done so in a health system that aims for universal access yet provides a fixed annual budget for this. Pharmac stands out internationally. Compared with, for example, the UK's National Institute for Health and Clinical Excellence and Australia's Pharmaceutical Benefits Advisory Committee, Pharmac is distinctive in that it manages all processes involved in decision making around assessing and listing publicly subsidised medicines, as well as negotiating prices with suppliers, all within a capped budget [1].

Pharmac's primary role is management of the Pharmaceutical Schedule. This features around 2,000 publicly subsidised prescription medicines listing them by chemical and brand name and including wholesale and retail prices, along with government subsidy levels. For pharmaceutical companies, a listing on the schedule is important for various reasons. First, government subsidies for listed medicines mean New Zealand residents pay a present cost of NZ\$5.00 (US\$4.20) per prescribed item, well below the copayment in many other high-income countries. Second, prescribers are more likely to prescribe medicines listed on the schedule. Third, a pharmaceutical company has a virtually guaranteed market for its products when listed compared with those that are not listed on the schedule. This is because patients bear the full cost of unlisted pharmaceuticals.

Unique amongst agencies in New Zealand's publicly funded healthcare system, Pharmac has largely escaped the many reforms and restructurings that have occurred since 
1993 [2]. Even the central Ministry of Health, the government's key advisor and policy agency, has endured a series of major internal restructurings. Pharmac's establishment in 1993 happened in the midst of building a competitive market-oriented system for delivering public health services to New Zealanders. The 1990s saw two further major reorganisations of the health system. From 1996 to 1999 , the four purchasers were merged into a single national agency, and public hospitals were required to collaborate rather than compete with one another. In 1999, the present health system arrangements were unveiled. These have since undergone periodic adjustments and there have been other changes in areas such as primary care. A further set of changes has been underway since 2008 , focusing on improving system and provider efficiency, coordination and quality of care [3].

In this context, why has Pharmac endured, how has it performed and how is it perceived? The agency has never been far from controversy, both within and beyond New Zealand. This is mostly owing to the fact that it has been successful when it comes to containing pharmaceutical expenditure, the techniques it deploys for this and some of the politics surrounding Pharmac decisions. Naturally, controversy and cost containment has brought the agency to the attention of policy makers around the world. However, Pharmac has also raised the ire of the pharmaceutical industry, various clinicians, researchers and patient groups. Some would like to see the agency gone, or at least its powers curtailed. Others see Pharmac as ahead of its time and to be emulated by policy makers elsewhere.

This article reflects on the history and role of Pharmac today. First, it looks at the original context within which it was developed, its aims and how it has approached its task. Next, it summarises Pharmac's performance. Third, the article describes the challenges Pharmac has faced over time, including those presented by the Trans-Pacific Partnership Agreement (TPPA) negotiations, and of new personalised medicines. Finally, it looks at potential lessons for other health systems.

\section{Pharmac from Birth to Present}

The circumstances surrounding Pharmac when it was founded are not to be overlooked. As noted, the overriding objective of policy makers at the time was to create a public health system infused with values of private business and competition. Pharmac was established by four independent government purchasing agencies, themselves just created in 1993. The Pharmaceutical Schedule had previously been a responsibility of the Department of Health, a unit within which had undertaken much of the ground work that informed Pharmac's subsequent activities [4]. The four new purchasers saw benefit in creating a single independent company able to use monopsony power to manage the Pharmaceutical Schedule. In this way, Pharmac's founding brought together disciplines of business (seeking the best deal and working within budget) and science (ensuring availability of safe and cost-effective medicines for New Zealanders).

The process of 'imprinting', where the values of founders are inked on an organisation [5], has meant Pharmac has continued to function with an ethos that reflects that of its early years. While the relationship between Pharmac and the pharmaceutical industry has improved over time and is today one of mutual, albeit at times uneasy, acceptance, at the outset Pharmac sought to attack pharmaceutical prices, and some might suggest the pharmaceutical industry, head on. This is partly owing to Pharmac's number one objective: to purchase an adequate range of pharmaceuticals for New Zealanders (maximising the contribution of medicines to the health of the population) within a fixed budget. Active negotiation of pharmaceutical costs and active management of the Pharmaceutical Schedule was seen as core to meeting this objective. There was a concerted belief amongst Pharmac's founders that New Zealand paid far too much for pharmaceuticals with considerable potential to reduce and contain the national pharmaceutical bill with the right negotiating tactics. Pharmac, of course, also was founded in a country with a restricted medicines industry mostly focused on generics. Unlike other countries where the pharmaceutical industry is a significant economic contributor, there was limited economic gain for New Zealand through government support for industry-set prices and no political risk in the negotiating tactics Pharmac developed. Unforseen at the time of creation, Pharmac has grown to provide an important balance in a context of direct-to-consumer advertising of pharmaceuticals, which is permitted in only New Zealand and the USA. Finally, and very importantly, Pharmac has multi-party support in New Zealand's Parliament.

\subsection{Pharmac's Functions and Processes}

Pharmac manages the costs of items already on the Pharmaceutical Schedule and also makes decisions around new inclusions. Most of the tactics used for the former had been deployed in a limited way when the Department of Health managed the Pharmaceutical Schedule [4]. The first of these is reference pricing in which Pharmac pays only the price of the cheapest pharmaceutical in a particular class, such as ACE inhibitors. The costs over the reference price for 
pharmaceuticals whose suppliers fail to meet this will be worn by patients, meaning they have a higher co-payment. This drives prescribers toward selecting the pharmaceutical with the reference price, while driving down costs of competing products. Second, Pharmac pursues cross-company deals in which it agrees, for example, to list a new medicine at an agreed price in exchange for the manufacturer lowering the cost of other listed medicines-sometimes having a spin-off effect of creating new reference prices. Third, the agency has a policy of promoting generics through tendering out the right to exclusive supply of a medicine for a fixed period once its patent has expired. Fourth, subsidies for various pharmaceuticals are restricted to patients most likely to benefit from them. In other scenarios, an expenditure cap on a pharmaceutical for a particular condition may be agreed on between Pharmac and the supplier. If more than the capped level of a product is prescribed the supplier funds the cost difference through refunding subsidies paid.

For new inclusions on the schedule, Pharmac underpins its decisions with criteria listed in Box 1 (in 2013, Pharmac engaged in a community consultation in view of producing an updated set of criteria, which remains under consideration at the time of writing) [6]. Very importantly, Pharmac prides itself in focusing on the use of evidence and economic analyses to inform decisions [7, 8]. In this regard, Pharmac has been a leader on the international stage in demanding transparency from a pharmaceutical industry that has been censured for selectivity when it comes to providing data [9]. However, the agency has itself been subject to ongoing questions around its decision-making processes, with suggestions that these are not as transparent as Australia's [10].

The decision whether to list a new medicine on the schedule follows a series of steps that involve a pharmaceutical company supplying results of clinical trials, the treatment benefits of their product and its costs. These data are assessed by Pharmac's Pharmacology and Therapeutics Advisory Committee, the recommendations of which Pharmac is not bound by. Arguably, Pharmac's primary focus is cost containment and prioritisation of medicines within its annual budget. It uses cost-utility analysis techniques to inform its decisions and make trade-offs between different medicine investments [6]. Thus, the agency may need to balance whether a new and more expensive medicine, which perhaps benefits a small number of patients, provides a better investment than another already listed medicine that benefits a wider population.
Box 1: Pharmac's decision-making criteria

- the health needs of all eligible people within New Zealand;

- the particular health needs of Māori and Pacific peoples;

- the availability and suitability of existing medicines, therapeutic medical devices and related products and related things;

- the clinical benefits and risks of pharmaceuticals;

- the cost effectiveness of meeting health needs by funding pharmaceuticals rather than using other publicly funded health and disability support services;

- the budgetary impact (in terms of the pharmaceutical budget and the Government's overall health budget) of any changes to the Pharmaceutical Schedule;

- the direct cost to health service users;

- the Government's priorities for health funding, as set out in any objectives notified by the [government] to Pharmac, or in Pharmac's Funding Agreement, or elsewhere; and

- such other criteria as Pharmac thinks fit. Pharmac will carry out appropriate consultation when it intends to take any such 'other criteria' into account.

Source: pharmac.health.nz

As in any country, there are periodic community demands for high-cost pharmaceuticals for specific conditions that affect only a very small number of patients. Until 2011, Pharmac maintained a 'Community Exceptional Circumstances' funding category designed for conditions where there were fewer than ten sufferers requiring medicines not listed on the Pharmaceutical Schedule [11]. An application for exceptional circumstances had to be submitted via a patient's general practitioner, and frequently these were for terminal, rare or incurable conditions. Sometimes, applications were for new medicines around which information on efficacy was limited. Applications needed to be balanced in the context of Pharmac's total budget, with the implication that any successful application for a specific medicine could open the way to others. There was an element of mystery surrounding the decisionmaking process. Success rates were not high and allegedly tended to hinge on how well the application was prepared [12]. In 2011, the exceptional circumstances category was replaced by a new Named Patient Pharmaceutical Assessment (NPPA) policy with a broader ambit. The NPPA features three application categories (see Box 2) and, like its predecessor, is notable for the fact that an applicant's social circumstances are not taken into account. As highlighted elsewhere, this contrasts with the assessment pro- 
cess for elective surgery in New Zealand [13]. To be fair, information about the impact on patients unable to access specific medicines is limited and more research into this is needed, along with research into the impact of delays in accessibility of some medicines.

Box 2: Named patient pharmaceutical assessment categories

Unusual Clinical Circumstances for sufferers of 'rare' diseases for which pharmaceuticals are unlikely to be included on the Pharmaceutical Schedule

Urgent Assessment for individuals with conditions requiring urgent treatment who cannot await a decision for listing on the Schedule

Hospital Pharmaceuticals in the Community for patients better treated with unlisted medicines in the community as an alternative to hospital treatment

Pharmac's role has expanded over the years, in part as a reflection of its success and endurance. In 2002, for example, it was handed responsibility for buying medicines on behalf of all New Zealand public hospitals, where previously each hospital district had purchased its own medicines, resulting in reasonable savings [14]. From 2012, it took responsibility for the national immunisation schedule and, in 2013, launched the Hospital Medicines List to provide consistency in medicines availability across hospitals. Pharmac has also recently taken on responsibility for purchasing medical devices for the public hospital sector, meaning its budget and influence will continue to grow. Its effect elsewhere in New Zealand's health system is not to be overlooked. Indeed, a new agency, Health Benefits Limited, created in 2010, has explored applying some of Pharmac's approaches to the purchase and provision of hospital goods and services.

\section{Pharmac's Performance}

Pharmac's performance is debated and final judgement depends on perspective and experiences. On a range of indicators the agency has performed admirably. Pharmac's own assessments are annually reported and suggest consistent gains over two decades in bringing down pharmaceutical prices, increasing the range of subsidised medicines available to the New Zealand public and slowing expenditure growth. Within its first financial year, Pharmac had reduced expenditure growth by around half and it has maintained a per annum growth rate well below the OECD average ever since: from 2000 to 2009, New Zealand's growth rate averaged $2.5 \%$; from 2009 to 2011 it was $0.1 \%$ (by comparison, Australia's rates were 3 and $4.9 \%$, respectively) [15]. In 2013, the agency spent NZ\$734 million (US\$634 million) on pharmaceuticals for New Zealanders; in its absence, it claims this would have been triple at over NZ\$2 billion [16]. In 2011, New Zealand spent US\$298 on prescription medicines per capita compared with an OECD average of US\$495 (adjusted for purchasing power parity), making it one of the lowest spenders [17].

Against this background, Pharmac asserts that the range of subsidised medicines has continued to expand as cost savings through its negotiations have permitted. In 2013, for example, it listed 20 new pharmaceuticals and invested in 60 additional products (via NPPA and other routes), while saving \$NZ56.6 million through negotiating prices down on those of the previous year. The 2013 financial year was also the first in which it tendered out hospital medicines and it announced savings of \$NZ4.1 million, around $2 \%$ of this expenditure category. While the total number of applicants from patients with rare diseases or specific pharmaceutical requirements has increased by around $25 \%$ since introduction of the NPPA, the number of successful applications has correspondingly grown. Pharmac reported that, in 2013, 14 highly applied for NPPA medicines were moved into the Pharmaceutical Schedule, following a policy move to align the NPPA and schedule more closely [16].

In comparative terms, New Zealand pays the lowest prices amongst high-income countries for a list of 30 'most prescribed' medicines-around one-third of the costs for the USA and $70 \%$ of Australian and British prices [18]. There are numerous examples of individual New Zealand pharmaceutical prices and patient co-payment amounts that other countries and their citizens might only dream of [19]. Indeed, Australia continues to pay up to 13 times New Zealand's price for the commonly prescribed atorvastatin [20].

Very importantly, Pharmac has been relatively free from political interference, receiving funding from but independent of government, and fiercely resistant to pharmaceutical industry influence over its decisions. On only a small number of occasions have its decisions come under political fire. A high-profile recent case involving herceptin (Trastuzumab) saw Pharmac deciding to fund only a 12-week course rather than the full year funded in other countries. Detailed elsewhere, the end result of electioneering saw the incoming government bypassing Pharmac and directly funding herceptin for 52 weeks via the Ministry of Health [21].

Despite the apparent successes, Pharmac has been criticised. First, studies variously suggest that New Zealanders have access to a more limited range of medicines, which are older and less innovative, than comparator health systems meaning patients with specific diseases often wait longer for access knowing that medicines are publicly 
subsidised in other countries $[1,22]$. The implication is that Pharmac is to blame. Pharmac has defended its position for the reason that it must work within its budget and, along with others, pointed out that in other jurisdictions patient co-payments are often considerably higher than New Zealand's [23]. Second, there are arguments that Pharmac is anti-competitive in the methods used to reduce pharmaceutical prices, especially as its decisions and activities are not subject to New Zealand's competition laws. The US pharmaceutical industry, in particular, has opposed this on various grounds [24]. A third line of concern is that Pharmac's focus on keeping within its budget eclipses patient care and evidence-based medicine. Such arguments have surrounded decisions not to fund certain pharmaceuticals or to only make them available via a specialist rather than a general practitioner. They also are used by those declined funding under the NPPA and its predecessor. Concern has also periodically arisen when Pharmac has switched a brand of medicine, with impacts on quality of care. Examples include the highly publicised case of statins, with considerable cost savings for Pharmac, but alleged implications for patients [25-27].

\section{Present and Future Challenges}

Pharmac obviously has to grapple with issues that confront every health agency, especially living within its budget in the face of potentially untethered and ever-changing demands. A key current challenge in this regard is the emergence of so-called 'personalised medicines' targeted at specific conditions, especially cancers, and tailored for individuals. While Pharmac presently funds a range of cancer products designed for specific populations, a patient demand for an individualised pharmaceutical is presently likely to require an NPPA. Reflecting on this, Pharmac's 2013 consultation on its decision-making criteria noted that: 'targeted personalised therapies more generally may require us to re-think what we value in the health system, as pharmaceutical companies focus on lower volume niche products [which potentially have a cost implication for Pharmac and impact on capacity to fund other medicines]' [6]. Thus, another present challenge for Pharmac is producing a new set of decision criteria which, as noted, is in progress.

It is no secret that Pharmac has been on the agenda of the USA in negotiations for the TPPA. While New Zealand's political leaders have implied that Pharmac is nonnegotiable, several areas of concern to the US pharmaceutical industry have remained on the table. These include demands for greater transparency around the tendering and price negotiating processes; the right to request reviews of
Pharmac's decisions through creation of an appeals process (presently a pharmaceutical company can only resubmit a rejected application for listing on the Schedule, or take up a legal challenge); preventing use of referencing pricing; and provisions that would require Pharmac to engage in ongoing dialogue with the pharmaceutical industry, with potential to impact on Pharmac's operations [28].

\section{Conclusion}

Following its 20th anniversary, a number of conclusions can be drawn about Pharmac. It is without doubt a resounding success in many ways as discussed above and to be celebrated for this. Notably, Pharmac has managed to combine two functions that in most other health systems are separated: the assessment of medicines in both scientific and financial terms. Elsewhere, the latter is usually the job of 'someone else', creating continual pressure on funders to purchase pharmaceuticals for the public based on recommendations by another scientific body that has not necessarily viewed its decision-making processes in the context of affordability. Yet, it is this very combination residing in Pharmac that has engendered the most criticism and industry concern. Pharmac's utilitarian approach of providing the greatest good for the greatest number within its budget has worked well, with the caveat that some New Zealanders miss out on or have delayed access to medicines available in other countries [1,22]. The agency has also emerged as something of an international role model for evidence-informed decision making. In the future, new thinking around how to fund high-cost individualised medicines is needed. One option could be for Pharmac to work on agreements with manufacturers to fund such medicines for individuals only if they are seen to produce results, requiring something of a trial period in each case in the form of shared industry-government risk.

As noted elsewhere [24, 29], perhaps the key lesson from Pharmac over the years is that active management of a pharmaceutical schedule can produce savings while increasing public access to subsidised medicines, albeit with the caveat that access to some medicines can be delayed, restricted or denied. In this context, Pharmac has shown New Zealand and the international community that it is possible to prioritise using methods that can withstand scrutiny and time. While no approach is perfect, and as noted there are various areas that Pharmac could and has sought to improve upon in its tasks, the agency is arguably better than the alternatives.

Author's declaration The author declares no conflict of interest. No funding for this work was received. 


\section{References}

1. Ragupathy R, Aaltonen K, Tordoff J, Norris P, Reith D. A threedimensional view of access to licensed and subsidized medicines under single-payer systems in the US, the UK, Australia and New Zealand. Pharmacoeconomics. 2012;30(11):1051-65.

2. Gauld R. Revolving doors: New Zealand's health reforms: the Saga continues. Wellington: Institute of Policy Studies and Health Services Research Centre; 2009.

3. Gauld R. New Zealand's post-2008 health system reforms: toward re-centralization of organizational arrangements. Health Policy. 2012;106:110-3.

4. Clark H. Pharmaceutical costs and regulation: from the Minister's desk. In: Davis P, editor. For health or profit? Medicine, the pharmaceutical industry, and the state in New Zealand. Auckland: Oxford University Press; 1992. p. 53-74.

5. Wilson JQ. Bureaucracy: what government agencies do and why they do it. New York: Basic Books; 1989.

6. Pharmaceutical Management Agency. Pharmac's decision criteria: consultation document. Wellington: Pharmaceutical Management Agency; 2013.

7. Grocott R. Applying programme budgeting marginal analysis in the health sector: 12 years of experience. Expert Rev Pharmacoecon Outcomes Res. 2009;9(2):181-7.

8. Grocott R, Metcalfe S, Alexander P, Werner R. Assessing the value for money of pharmaceuticals in New Zealand: Pharmac's approach to cost-utility analysis. N Z Med J. 2013;126(1378): 60-73.

9. Goldacre B. Bad pharma: how drug companies mislead doctors and harm patients. London: Fourth Estate; 2012.

10. Milne R, Wonder M. Response to Pharmac on access to new medicines in New Zealand compared to Australia. N Z Med J. 2011;124(1347):91-3.

11. Rasiah D, Edwards R, Crampton P. Funding community medicines by exception: a descriptive epidemiological study from New Zealand. N Z Med J. 2012;125(1350):21-9.

12. Coyle G. How does the operation of Pharmac's 'Community Exceptional Circumstances' policy align with the distributive justice principles of fairness and equity as described by John Rawls and Amartya Sen? Auckland University of Technology PhD thesis; 2012.

13. Manning J. Exceptional circumstances schemes and the social factors exclusion in healthcare rationing. Oxford Univ Commonwealth Law J. 2013;13(1):75-114.
14. Tordoff J, Norris P, Reith D. 'Price management' and its impact on hospital pharmaceutical expenditure and the availability of medicines in New Zealand. Value Health. 2008;11(7):1214-26.

15. OECD. Health at a Glance 2013. Paris: OECD; 2013.

16. Pharmaceutical Management Agency. Pharmaceutical Management Agency. Annual Review 2013. Wellington: Pharmaceutical Management Agency; 2013.

17. OECD. OECD Health Data. Paris: OECD; 2013.

18. The US health system in perspective: a comparison of twelve industrialized nations. New York: Commonwealth Fund; 2011.

19. Cobiac L. Pharmac looks great value for money: an Australian perspective. N Z Med J. 2012;125(1358):82-3.

20. Duckett S, Breadon P, Ginnivan L, Venkararaman P. Australia's bad drug deal: high pharmaceutical prices. Melbourne: Grattan Institute; 2013.

21. Fenton E. Making fair funding decisions for high cost cancer care: the case of herceptin in New Zealand. Public Health Ethics. 2010;3(2):137-46.

22. Wonder M, Milne R. Access to new medicines in New Zealand compared to Australia. N Z Med J. 2011;124(1346):12-28.

23. Moodie P, Metcalfe S, Poynton M. Do pharmaceutical score cards give us the answers we seek? $\mathrm{N} Z$ Med J. 2011;124(1346):69-74.

24. Cumming J, Mays N, Daube J. How New Zealand has contained expenditure on drugs. BMJ. 2010;340(c2441):1224-7.

25. Begg E, Sidwell A, Gardiner S, Nicholls G, Scott R. The sorry saga of the statins in New Zealand: pharmacopolitics versus patient care. N Z Med J. 2003;116(1170):U360.

26. Ellis CJ, White H. Pharmac and the statin debacle. N Z Med J. 2006;119(1236).

27. Moodie P, Dougherty S, Metcalfe S. Pharmac and statins: getting the best population health gains. N Z Med J. 2006;119(1238):1-3.

28. Gleeson D, Lopert R, Reid P. How the Trans Pacific Partnership Agreement could undermine Pharmac and threaten access to affordable medicines and health equity in New Zealand. Health Policy. 2013;112:227-33.

29. Davis P. Tough but fair? The active management of the New Zealand Drug Benefits Scheme by an independent crown agency. Aust Health Rev. 2004;28(2):171-81. 